\title{
Promoção dos direitos da criança e prevenção de maus tratos infantis
}

\author{
Promotion of children's rights and prevention of child abuse
}

Cleiciara Lúcia Silva Ferreira (http://orcid.org/0000-0001-8238-050X) ${ }^{1}$

Maria Conceição J. Werneck Côrtes (http://orcid.org/0000-0002-3749-2841) ${ }^{2}$

Eliane Dias Gontijo (https://orcid.org/0000-0002-7518-898X) ${ }^{2}$
${ }^{1}$ Programa de PósGraduação da Faculdade de Medicina, Universidade Federal de Minas Gerais (UFMG). Av. Prof. Alfredo Balena 190, Santa Efigênia. 30130-100 Belo Horizonte MG Brasil.

cleiciara@yahoo.com.br

${ }^{2}$ Departamento de Medicina Preventiva e Social,

FMUFMG. Belo Horizonte MG Brasil.

\begin{abstract}
Child abuse is a complex, multi-faceted and controversial topic. A retrospective cohort study aimed to characterize the profile of children victims of domestic violence and their aggressors and to evaluate the efficiency of judicial interventions. Ninety-eight cases lodged with the Infancy and Childhood Court involving 179 children and 121 perpetrators were analyzed. Negligence/abandonment (62\%) and physical violence (30\%) were the most frequent violations. Mothers were identified as the most frequent aggressor; monthly income of up to one minimum wage and history of alcohol use have been associated with violence. Seventy-one percent of victims were enrolled in educational institutions. In $25 \%$ of the cases the severity of the abuse required the removal of the child from the family. A third of the children were enrolled in official programs designed to provide the family with support, orientation and follow $-u p$. This protective judicial intervention was successful in reducing abuse in 93\% of the cases within 2 years. Prevention of child abuse requires the involvement of professionals of multiple fields at an early stage. The promotion and safeguarding of children's rights must come primarily from the implementation of public policy not judicial intervention.

Keywords Child Abuse, Judicialization, Children's rights, Cohort Studies.
\end{abstract}

Resumo A violência praticada contra crianças é tema complexo e polissêmico. Estudo de coorte retrospectiva buscou caracterizar o perfil das crianças vítimas de violência doméstica e de seus agressores e avaliar a eficácia das intervenções judiciais. Analisou-se 98 processos da Vara da Infância e Juventude, envolvendo 179 crianças e 121 agressores. Negligência/abandono e violência física foram as violações mais frequentes. Revelou-se a mãe como principal agressora; renda mensal de até um salário mínimo e história de uso de álcool mostraram-se associados à violência. Encontrouse $71 \%$ das vitimas matriculadas em instituições de ensino. Em $25 \%$ a gravidade da situação determinou o afastamento da família. Um terço das crianças foram incluídas em programas de apoio, orientação e acompanhamento à família. A intervenção judicial garantiu 93\% de interrupção da violência em até dois anos, tempo ainda longo, pelo risco da criança ser revitimizada. Ações efetivas pressupõem o envolvimento da família, da sociedade, das instituições escolares e de saúde. A garantia de direitos tem na execução das políticas públicas, e não na judicialização, o lócus privilegiado de efetivação.

Palavras-chave Violência infantil, Maus-Tratos Infantis, Judicialização, Direitos da criança, Estudo de Coorte. 


\section{Introdução}

A violência contra crianças constitui fenômeno global, complexo e endêmico, exigindo ações imediatas e efetivas para sua superação. Cotidianamente, crianças são vitimadas. O domicílio considerado socialmente como ambiente de proteção, segurança e afeto, passa a ser cenário de agressão.

A partir do Estatuto da Criança e do Adolescente, em 1990, várias iniciativas foram implantadas visando à sua proteção. A criança e o adolescente passam a ser considerados titulares de direitos e sujeitos que devem ser protegidos pelo Estado, pela sociedade e pela família. Assim, as ações violentas tornaram-se objeto de estudo e intervenção direta em diferentes segmentos sociais $^{1,2}$.

No Brasil, o dimensionamento da violência infantil é ainda precário, mas avanços têm surgido como a implantação de um Sistema de Informação para a Infância e Adolescência (Sipia) ${ }^{3}$, em 2013, ligado ao Ministério da Justiça, para o monitoramento contínuo da situação de proteção à criança e ao adolescente, porém com acesso ainda restrito aos Conselhos Tutelares e às Unidades/Programas de Atendimento Socioeducativo, com exigência de senha.

Outra importante fonte de informação é o Sistema de Vigilância de Violências e Acidentes (VIVA). Desde 2011, os profissionais de saúde estão obrigados a notificar qualquer caso de violência doméstica ou sexual que atenderem ou identificarem ${ }^{4}$. Em 2014, foram notificados 22.669 casos de violência contra crianças menores de 10 anos, sendo que $58 \%$ referem-se à negligência/abandono $\mathrm{o}^{5}$. Na faixa entre 10 e 14 anos há um incremento de 17 mil violações de direito, principalmente por violência física e sexual, totalizando aproximadamente 40 mil casos de violência em menores de 14 anos.

A violência, dada sua natureza polissêmica, assume significados de acordo com épocas, locais e circunstâncias necessitando de abordagem multidisciplinar e intersetorial ${ }^{6}$. Os serviços de saúde e as instituições escolares podem ser os primeiros a identificarem sinais de maus tratos e, portanto, atuarem como Unidades Sentinelas. A notificação compulsória da violência deve ser compreendida como um instrumento de garantia de direitos e proteção social, por possibilitar a identificação de casos concretos de violação. Permite, ainda, aos profissionais das áreas de saúde, educação, assistência social, conselhos tutelares e ao Poder Judiciário adotarem medidas intersetoriais mais efetivas de cuidado às vítimas?
Muitas foram as conquistas no campo dos direitos da infância no Brasil. No entanto, sua garantia, reconhecimento e efetivação têm demandado lutas históricas, e a intervenção de diferentes setores, dentre eles o Poder Judiciário, convocado a intervir para a cessação da violência sofrida.

$\mathrm{O}$ atendimento de denúncias de criança em situação de violência inicia-se habitualmente pelo Conselho Tutelar, que após esgotar as possibilidades de intervenção junto às famílias e constatando a necessidade de ações que ultrapassam seu campo de atuação, deverá encaminhar os casos ao Ministério Público (MP) considerado o curador dos direitos da infância ${ }^{8}$ que, por sua vez, poderá ou não determinar o encaminhamento do caso à esfera judiciária. Nessa instância, a denúncia adquirirá o status de processo judicial, demandando decisão do Juiz responsável pela Vara da Infância e Juventude.

Após a abertura do inquérito, as evidências identificadas pela área técnica podem levar ao arquivamento da notificação ou instauração de processo. A intervenção judicial é decisiva e varia desde a destituição do poder familiar, determinação de medidas terapêuticas para a família, interdição de permanência e de contato com a criança vítima ou, até mesmo, da prisão do agressor ${ }^{9}$.

Assim, o Poder Judiciário situa-se na extremidade final da rede de proteção e da garantia de direitos das crianças, devendo ser acionado, somente quando todas as tentativas de interrupção da violência tiverem sido esgotadas.

No entanto, a indefinição acerca do papel de cada instituição nos casos de violência, além da representação social da Justiça como o único meio de solucionar conflitos incentivam o encaminhamento de problemas que poderiam ser resolvidos na interlocução com outros equipamentos da sociedade. A situação de risco identificada necessita de atenção especial dos gestores públicos e da atuação efetiva dos Conselhos Tutelares, evitando a judicialização regular de tais ações, incrementando a parceria com as demais instâncias de proteção à criança ${ }^{10}$.

Fatores como o número excessivo de denúncias, a insuficiência de funcionários, a qualificação inadequada e a má qualidade dos registros podem atrasar as decisões pelo Poder judiciário ${ }^{11,12}$.

Buscando compreender a atuação do Judiciário no enfrentamento da violação de direitos da criança, o presente artigo tem como objetivo caracterizar o perfil das crianças vítimas de violência doméstica e de seus agressores e avaliar a eficácia das intervenções judiciais. 


\section{Metodologia}

Trata-se de estudo de coorte retrospectiva com análise dos processos de denúncias de violências praticadas contra crianças, encaminhados em 2011 à Vara da Infância e Juventude de município de médio porte, com 230 mil habitantes, sendo $18 \%$ da população na faixa etária até 12 anos.

Os dados referentes à vítima, ao agressor e aplicação de medidas protetivas foram obtidos dos laudos psicossociais dos processos envolvendo crianças vítimas de violência, na faixa etária de zero a doze anos incompletos, elaborados pela equipe técnica, formada por assistentes sociais e psicólogos, treinados em técnicas de escuta qualificada, que avaliam a realidade social e psicológica das famílias e incluem as observações realizadas ao longo de todo o processo.

O diagnóstico de situação de risco e de sua interrupção é feito pela mesma equipe e utiliza instrumentos padronizados incluindo entrevistas individuais ou em grupos, buscando conhecer as pessoas envolvidas, sua realidade social e/ou psicológica; seguida de discussão pela equipe. $\mathrm{O}$ processo inclui ainda visita domiciliar para esclarecimentos e atestar a veracidade dos depoimentos, além de visitas institucionais como unidade de saúde, escola, projetos, serviços e outros, dependendo do tipo de violação e das medidas instituídas. Esses estudos fundamentam a decisão inicial do Juiz tanto sobre a existência da situação de risco e consequente definição das medidas protetivas, como a permanência ou interrupção da violação de direito.

A eficácia das intervenções foi avaliada pelo tempo decorrido entre a denúncia e a interrupção da situação de risco e proporção de processos resolvidos. As variáveis estudadas incluíram: número do processo, situação (ativo ou arquivado), tipo de ação, ano de origem, órgão denunciante, número de crianças envolvidas.

Para a identificação da vítima obteve-se dados referentes à idade, sexo, residência, escolaridade e tipo de violência sofrida. $\mathrm{O}$ agressor foi caracterizado quanto ao sexo, parentesco com a criança, envolvimento com drogas lícitas e ilícitas e autorrelato de doença psiquiátrica. Acerca da medida protetiva observou-se: tipo, lapso temporal de sua aplicação, instituição responsável pela sua operacionalização e acompanhamento sistemático da família, tempo entre a instauração do processo e a primeira intervenção do setor psicossocial, necessidade de reavaliação do caso pelo setor técnico e permanência ou não da criança na situação de risco inicial.
Realizou-se análise descritiva dos dados, calculando-se frequência absoluta e relativa e análise univariada de características das vítimas e dos agressores por tipo de violência. Estimou-se o tempo entre os eventos e sua resolução utilizando-se o método de Kaplan Meyer. Em todos os testes foi considerado o nível de significância de $5 \%$.

O programa SPSS 19.0 for Windows foi utilizado para a organização e análise dos dados. A pesquisa foi aprovada, na Plataforma Brasil, pelo Comitê de Ética e Pesquisa Envolvendo Seres Humanos.

\section{Resultados}

Foram identificados 98 processos que envolveram 179 crianças vítimas de violência e 121 agressores.

No momento da denúncia, a violência foi assegurada pelo declarante em $74 \%$ dos casos e informada como suspeita em $26 \%$. Após avaliação pela equipe técnica confirmou-se a violação de direitos em $90 \%$ das denúncias e nove processos foram excluídos por insuficiência de evidências para comprovação.

Negligência/abandono (62\%), seguida de violência física $(30 \%)$ foram as violações de direitos mais frequentes. Abuso sexual (6\%) e violência psicológica $(2 \%)$ foram os menos usuais. Dentre as famílias avaliadas, $74 \%$ possuíam renda igual ou inferior a um salário mínimo e 70\% eram compostas por três ou mais moradores. O Conselho Tutelar foi responsável pelo encaminhamento de $53 \%$ das denúncias. As demais foram encaminhadas diretamente ao Ministério Público e, posteriormente ao Poder Judiciário.

Entre as 179 crianças envolvidas nos processos, 56\% tinham idade até cinco anos; e 44\% tinham entre seis e doze anos incompletos, com predomínio de vítimas do sexo feminino $(53 \%)$ (Tabela1). Verificou-se que $71 \%$ estavam matriculadas em instituições de ensino.

Segundo informações constantes nos processos, todas as vítimas residiam com familiares, sendo que a mãe estava presente no lar em $81 \%$ dos casos analisados: $11 \%$ moravam apenas com a genitora; $27 \%$ residiam com ambos os pais; $53 \%$ moravam com a mãe e demais membros da família e somente $9 \%$ não moravam com nenhum dos genitores.

A violência foi praticada, em sua maioria, por um único agressor (64\%), do sexo feminino (63\%). Cerca de $70 \%$ estavam desempregados ou 
não possuíam vínculo empregatício formal, durante a tramitação do processo judicial. A mãe foi citada como autora em $46 \%$ dos processos, o pai em $10 \%$ deles, ambos os genitores (pai e mãe) em $30 \%$ e outros agressores em $13 \%$. A doença psiquiátrica foi autorelatada por $5 \%$ dos agressores (Tabela 2).

Renda mensal igual ou inferior a um salário mínimo (79\%), o relato da presença da mãe entre os agressores $(82 \%)$ e história de uso de álcool (79\%) mostraram-se como características estatisticamente associadas à violência $(\mathrm{p}<0,05)$. Por outro lado, o uso de droga ilícita $(\mathrm{p}=0,29)$ e composição familiar $(\mathrm{p}=0,25)$ não estavam associadas à violência doméstica contra a criança, independentemente da tipologia. (Tabela 3).

Observou-se que baixa renda, mãe como agressora e o uso de álcool estavam associados com a violência $(p<0,05)$. Não houve associação entre composição familiar e uso de droga ilícita.

Em todos os processos comprovados foram aplicadas medidas protetivas. Um terço das crianças foi encaminhado para inclusão em programas oficiais de apoio, orientação e acompanhamento à família, sendo $12 \%$ referentes à inclusão em programas junto à política de assistência social; $17 \%$ inclusão em programa oficial ou comunitário de auxílio, orientação e tratamento de alcoólatras e toxicômanos, requisição de tratamento médico, psicológico, psiquiátrico, em regime hospitalar ou ambulatorial, junto à política de saúde e $1,4 \%$ das crianças, que estavam fora da escola, foram encaminhadas para matrícula e frequência obrigatória em estabelecimento oficial de ensino.

Tabela 1. Perfil da vítima nos processos judiciais de violência infantil, atendidos na Vara de Infância e Juventude, Município de médio porte, MG, 2011

\begin{tabular}{lcc}
\hline \multicolumn{1}{c}{ Características } & N & $\%$ \\
\hline Idade & & \\
$\quad<1$ ano & 13 & 7,3 \\
De 1 a 5 anos & 88 & 49,2 \\
$\quad$ De 6 a 12 anos & 78 & 43,6 \\
Sexo & & \\
$\quad$ Feminino & 95 & 53,1 \\
$\quad$ Masculino & 84 & 46,9 \\
Tipo violência & & \\
$\quad$ Negligência/Abandono & 55 & 61,8 \\
$\quad$ Física & 27 & 30,3 \\
Sexual & 5 & 5,6 \\
$\quad$ Psicológica & 2 & 2,2 \\
\hline
\end{tabular}

* Em nove processos não foram confirmadas violações de direito.
Em 25\% dos processos houve necessidade de afastar a criança da família por meio das medidas de transferência da guarda ou de tutela a terceiros $(12,3 \%)$, abrigo em entidade (11,4\%) e colocação em família substituta (1\%).

Quanto à instituição responsável pela operacionalização das medidas aplicadas, $53 \%$ foram executadas pelo setor psicossocial do próprio judiciário; 19\% por serviços da política de assistência social; $10 \%$ por equipamentos da política de saúde; $2,0 \%$ por equipamentos da política de educação e $14 \%$ por instituição de acolhimento.

A análise do tempo entre o protocolo da denúncia e a realização do estudo psicossocial revelou que em quatro meses $53 \%$ dos processos já tinham sido avaliadas pela equipe técnica. Após 12 e 24 meses, respectivamente, $87 \%$ e $96 \%$ dos processos haviam sido analisados e medidas protetivas recomendadas.

Tabela 2. Perfil do agressor citado nos processos judiciais de violência infantil, atendidos na Vara de Infância e Juventude, Município de médio porte, MG, 2011

\begin{tabular}{|c|c|c|}
\hline & $\mathbf{N}$ & $\%$ \\
\hline \multicolumn{3}{|l|}{ Agressor $(\mathrm{n}=121)$} \\
\hline Um & 57 & 64,0 \\
\hline Dois & 32 & 36,0 \\
\hline \multicolumn{3}{|l|}{ Relação com a vítima } \\
\hline Pai & 9 & 10,1 \\
\hline Mãe & 41 & 46,1 \\
\hline Mãe e pai & 27 & 30,3 \\
\hline Padrasto & 1 & 1,1 \\
\hline Mãe a padrasto & 4 & 4,5 \\
\hline Avós & 4 & 4,5 \\
\hline Professora & 1 & 1,1 \\
\hline Primo(a) & 1 & 1,1 \\
\hline Filhos da madrasta & 1 & 1,1 \\
\hline \multicolumn{3}{|l|}{ Sexo } \\
\hline Feminino & 76 & 62,8 \\
\hline Masculino & 45 & 37,2 \\
\hline \multicolumn{3}{|l|}{ Trabalho } \\
\hline Trabalhador formal & 10 & 8.3 \\
\hline Trabalhador informal & 35 & 28,9 \\
\hline Desempregado & 71 & 58,7 \\
\hline Aposentado & 2 & 1,7 \\
\hline Sem informação & 3 & 2,5 \\
\hline \multicolumn{3}{|c|}{ Relata presença de doença psiquiátrica } \\
\hline Sim & 6 & 5,0 \\
\hline Não & 109 & 90,1 \\
\hline Sem informação & 6 & 5,0 \\
\hline
\end{tabular}


Tabela 3. Características da família e do agressor por tipo de violência praticada, em processos judiciais de violência infantil, atendidos na Vara de Infância e Juventude, Município de médio porte, MG, 2011

\begin{tabular}{|c|c|c|c|c|c|c|c|c|c|}
\hline & \multicolumn{6}{|c|}{ Tipologia violência } & \multicolumn{2}{|c|}{ Total } & \multirow[t]{3}{*}{$p$ valor } \\
\hline & \multicolumn{2}{|c|}{ Física } & \multicolumn{2}{|c|}{ Sexual } & \multicolumn{2}{|c|}{$\begin{array}{c}\text { Negligência/ } \\
\text { abandono }\end{array}$} & \multirow[b]{2}{*}{$\mathbf{n}$} & \multirow[b]{2}{*}{$\%$} & \\
\hline & $\mathrm{N}$ & $\%$ & $\mathbf{N}$ & $\%$ & $\mathbf{N}$ & $\%$ & & & \\
\hline \multicolumn{10}{|l|}{ Renda mensal } \\
\hline$\leq 1$ salário mínimo & 16 & 64,0 & 2 & 50,0 & 42 & 89,4 & 60 & 78,9 & $0.028^{*}$ \\
\hline 2 salários mínimos & 8 & 32,0 & 2 & 50,0 & 3 & 6,4 & 13 & 17,1 & \\
\hline$\geq 3$ salários mínimos & 1 & 4,0 & 0 & 0,0 & 2 & 4,3 & 3 & 3,9 & \\
\hline \multicolumn{10}{|l|}{ Composição lar } \\
\hline Pai e mãe & 8 & 29,6 & 1 & 20,0 & 15 & 27,3 & 24 & 27,6 & 0.253 \\
\hline Mãe & 2 & 7,4 & 0 & 0,0 & 8 & 14,5 & 10 & 11,5 & \\
\hline Mãe e outros & 14 & 51,9 & 2 & 40,0 & 29 & 52,7 & 45 & 51,7 & \\
\hline Outros & 3 & 11,1 & 2 & 40,0 & 3 & 5,5 & 8 & 9,2 & \\
\hline \multicolumn{10}{|l|}{ Agressor citado } \\
\hline Pai & 5 & 18,5 & 2 & 40,0 & 2 & 3,6 & 9 & 10,3 & $<0.001^{\star}$ \\
\hline Mãe & 12 & 44,4 & 0 & 0,0 & 28 & 50,9 & 40 & 46,0 & \\
\hline Pai e mãe & 4 & 14,8 & 0 & 0,0 & 23 & 41,8 & 27 & 31,0 & \\
\hline Padrasto & 0 & 0,0 & 1 & 20,0 & 0 & 0,0 & 1 & 1,1 & \\
\hline Mãe e padrasto & 4 & 14,8 & 0 & 0,0 & 0 & 0,0 & 4 & 4,6 & \\
\hline Outros & 2 & 7,4 & 2 & 40,0 & 2 & 3,6 & 6 & 6,9 & \\
\hline \multicolumn{10}{|l|}{ História de uso de álcool } \\
\hline Sim & 20 & 62,5 & 2 & 40,0 & 63 & 88,7 & 85 & 78,7 & $0.001^{\star}$ \\
\hline Não & 12 & 37,5 & 3 & 60,0 & 8 & 11,3 & 23 & 21,3 & \\
\hline \multicolumn{10}{|c|}{ História de uso de droga ilícita } \\
\hline Sim & 15 & 48,4 & 1 & 25,0 & 43 & 58,9 & 59 & 54,6 & 0.295 \\
\hline Não & 16 & 51,6 & 3 & 75,0 & 30 & 41,1 & 49 & 45,4 & \\
\hline
\end{tabular}

As determinações judiciais foram aplicadas em $54 \%$ dos casos no prazo de cinco meses; $81 \%$ em 12 meses e em $94 \%$ dos processos em até 24 meses (Gráfico 1).

Verificou-se diferença no intervalo de tempo entre o protocolo do processo e a aplicação da medida protetiva sendo menor nos referentes à violência física em relação à modalidade negligência (Gráfico 2).

A tipologia de violência sexual e psicológica não pôde ser comparada devido ao reduzido número de processos.

O monitoramento pela equipe técnica revelou que em 93\% dos processos as crianças haviam saído da situação de risco inicial. Em 24 meses, $42 \%$ dos processos protocolados foram arquivados, com percentual crescente atingindo $50 \%$ em 29 meses, 61\% em 36 meses e apenas sete casos (7\%) não foram resolvidos em até dois anos. Essas nove vítimas permaneciam em acompanhamento devido a não superação da violên- cia. A equipe técnica juntamente com a rede socioassistencial persistiam no acompanhamento, buscando o fortalecimento dos vínculos afetivos e emancipação da família.

\section{Discussão}

A violência praticada contra a criança no ambiente doméstico é reconhecida como tema complexo, polissêmico e controverso, o que impossibilita conclusões deterministas sobre o assunto ${ }^{5}$. A questão exige a participação efetiva de todos na garantia de proteção à criança em situação de risco e ações integradas devem ser priorizadas, visando maior eficiência das intervenções. O estudo revelou a importância do Conselho Tutelar, considerando que mais da metade das denúncias que chegaram ao Poder Judiciário se deu por esse órgão de defesa. Faz-se necessário garantir recursos para seu efetivo funcionamento, capacitação 


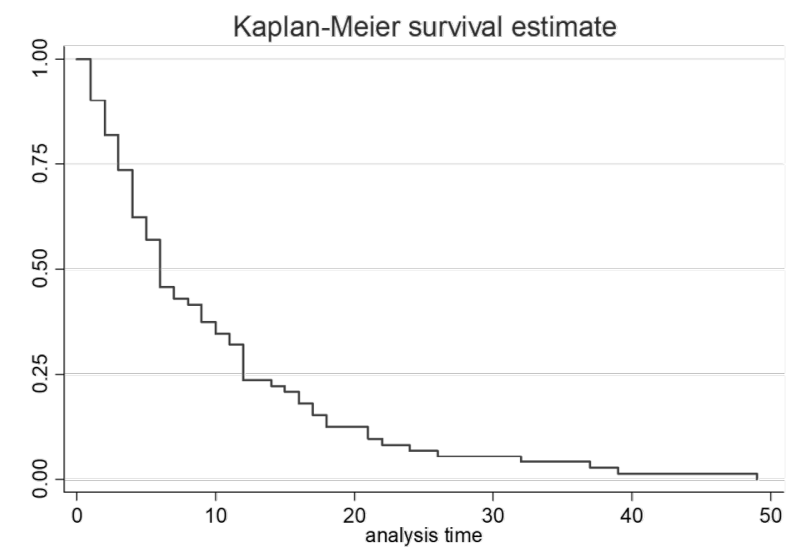

Gráfico 1. Tempo entre o protocolo da denúncia e a aplicação das medidas protetivas de processos judiciais de violência infantil, atendidos na Vara de Infância e Juventude, Município de médio porte, MG, 2011.

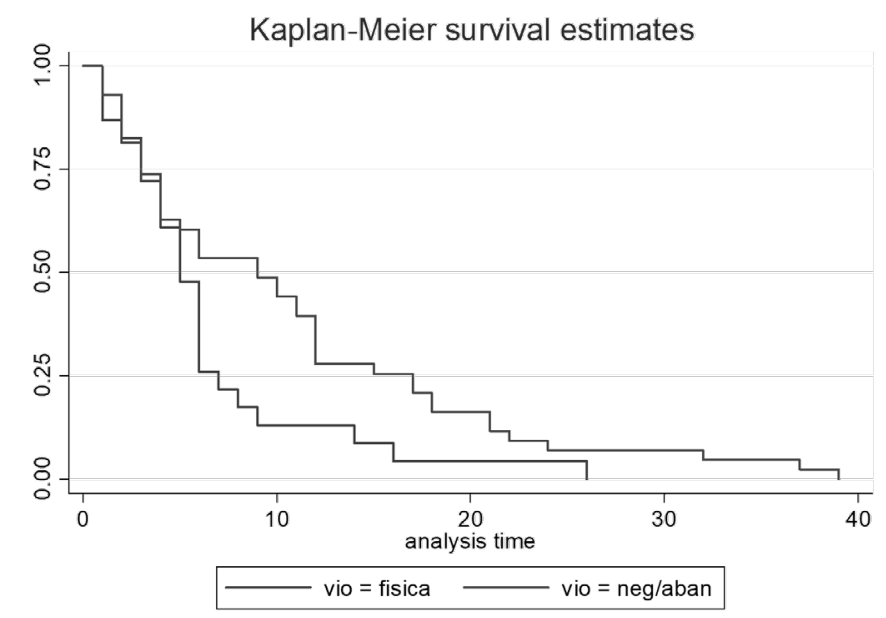

Gráfico 2. Tempo entre o protocolo da denúncia e aplicação das medidas protetivas nos processos referentes à negligência versus violência física, atendidos na Vara de Infância e Juventude, Município de médio porte, MG, 2011.

continuada de seus membros, viabilizando uma intervenção competente e qualificada. Por outro lado, o percentual expressivo de encaminhamentos feitos diretamente, pelo Ministério Público, antes da intervenção do Conselho Tutelar contraria o fluxo de atendimento da rede socioassistencial.
O Judiciário como última instância deveria receber casos de denúncias confirmadas e já atendidas por outros setores, esgotando-se, nestes espaços, todas as possibilidades de intervenção.

A análise dos processos judiciais revelando a predominância da violação de direitos entre as crianças até cinco anos sinaliza a importância da 
educação infantil, garantida em lei para crianças de 0 a 6 anos de idade, como instrumento de prevenção e garantia de proteção. A incapacidade de defesa, a fragilidade física e emocional, a permanência prolongada em casa em decorrência de vagas insuficientes em creches podem se constituir em possíveis explicações para a maior vulnerabilidade dessa faixa etária, consideradas as necessidades dos pais em se ausentarem para obter os recursos financeiros necessários a subsistência da família ${ }^{13-15}$.

O fato de a maioria das crianças vítimas de violência estarem inseridas em instituição escolar, devidamente matriculadas e frequentes, aponta a relevância dessa instância como importante agente no processo de identificação e notificação da violência, visto que depois da família a escola torna-se o segundo espaço social, onde a criança permanece grande parte de seu tempo. Faleiros et al. ${ }^{16}$ verificaram a prevalência de 5,7\% referente aos maus-tratos domésticos contra crianças, menores de dez anos, que frequentavam estabelecimentos educacionais. $\mathrm{O}$ estudo comprova que a estimativa oficial de $0,3 \%$ com os dados obtidos no Conselho Tutelar, representa somente a "ponta do iceberg".

Assim como as instituições escolares, os serviços de saúde também possuem papel relevante frente ao enfrentamento à violência infantil. A literatura aponta a abordagem limitada do problema, restrita, em geral, ao tratamento de lesões e traumas que resultam das agressões ${ }^{17}$, revelando o despreparo dos profissionais de saúde para lidar com a violência. Opta-se pela medicalização do fenômeno pela dificuldade em lidar com os aspectos sociais e a falta de proteção nos casos de denúncia de violência ${ }^{18}$.

O perfil das vítimas e agressores dos casos atendidos na Vara de Infância e Adolescência foi similar ao demonstrado em estudos realizados em outros cenários, espelhando a realidade epidemiológica da violência contra a criança. A predominância de meninas foi, também, encontrada por De Lorenzi et al. ${ }^{14}$ em estudo realizado em ambulatório especializado. O domicílio como local recorrente das diferentes formas de violência contra crianças confirma dados da literatura ${ }^{13} \mathrm{e}$ mostra-se um fator dificultador da notificação como acontecimento do contexto familiar, de difícil abordagem devido ao pacto de silêncio, considerado uma questão da esfera privada. $\mathrm{Na}$ violência doméstica destacam-se a cultura patriarcal e adultocêntrica, ou seja, o poder do homem e do adulto sobre a criança e a falta ou a dificuldade de diálogo no relacionamento entre pais e filhos.
A identificação da mãe como responsável pela agressão corrobora com o velamento dos fatos, frequência da presença da genitora e mostra-se consoante com estudos e pesquisas que abordam situações de violência infantil ${ }^{19,20}$. Esse achado contradiz o papel socialmente estabelecido em relação à mulher/mãe a quem é conferida o dever de cuidar e educar. Por outro lado, a negligência/ abandono como principal tipo de violência pode ser parcialmente explicado pelo estresse e sobrecarga diária decorrente do acúmulo de funções assumidas pela mulher na sociedade contemporânea, somando-se à responsabilidade pela educação dos filhos as exigências de prover as necessidades materiais do lar muitas vezes sozinha ${ }^{21,22}$.

Não foi observada associação estatística entre a composição do grupo familiar e a tipologia da violência, apesar de $72 \%$ das violações de direito terem ocorrido em lares sem a presença simultânea de pai e mãe. Dados do Ministério da Saúde apontam que crianças morando com apenas um dos pais, têm $80 \%$ a mais de riscos de sofrerem violência, duplicando a chance de serem negligenciadas $^{23}$.

A associação significativa $(\mathrm{p}<0,05)$ entre renda mensal igual ou inferior a um salário mínimo e violação de direitos, em especial a negligência/ abandono, sugere que dificuldades econômicas podem constituir em fator desencadeador de violência, pela privação ${ }^{22}$. Apesar de a violência doméstica estar presente em todas as classes e estratos sociais, sua distribuição é socialmente diferenciada e incide com maior frequência entre os mais pobres, indicando os limites das políticas sociais no Brasil que, ao priorizar o combate à pobreza extrema, pode não atender às necessidades sociais da população.

A pobreza e as desigualdades sociais resultam em um conjunto de relações e circunstâncias que afasta as pessoas dos seus direitos. A pobreza não deveria ser motivo para a retirada das crianças do convívio familiar, embora esta seja a solução possível na eminência de um dano maior ${ }^{22,24}$. Esse contexto demonstra os limites das ações sociais no Brasil, que têm como foco o combate à pobreza extrema, por meio de transferência de renda condicionada, que não consegue atender a todas as necessidades sociais dos sujeitos. As políticas de proteção social têm se caracterizado pelo atendimento às situações de alta vulnerabilidade, ou seja, aos mais pobres dentre os pobres, com enfoque em ações mais humanitárias do que política de direitos ${ }^{25}$. Como instrumento de intervenção do Estado na elevação da qualidade de vida da população as políticas públicas não devem se res- 
tringir a ações pontuais e imediatas, pelo contrário, fortalecer os valores humanos fundamentais, como a vida, a liberdade e a segurança.

O Poder Judiciário tem, sim, a atribuição legal e ética de fazer valer os direitos positivados. Entretanto, se houvesse uma efetiva implementação das políticas públicas, com garantia de acesso aos direitos fundamentais como educação, saúde, habitação e assistência social com qualidade, parte das ações, que hoje tramitam junto às Varas da Infância e Juventude, não chegariam a essa instância. Ressalte-se aqui que o processo judicial tem protocolos e burocracias a serem seguidas, que mesmo sendo céleres podem ser intempestivas numa situação de risco que pode se agravar em minutos como é o caso da violência. Em que pese sua resolução, trata-se de crianças em risco o que torna qualquer tempo urgente, ou curto ou insuficiente.

A associação significativa entre a ocorrência da violência e o uso de bebida alcoólica, bem como o desemprego, confirmam achado de Menezes et al. ${ }^{26}$ sobre o efeito do álcool incentivando a conduta violenta.

A violência psicológica, caracterizada por ameaças verbais foi pouco observada ${ }^{27,28}$. Por ser sutil, torna-se mais difícil de ser identificada e notificada, especialmente em crianças. Pesquisa realizada em estudantes de escolas particulares e públicas demonstrou que mais de 50\% dos estudantes sofreram agressões verbais cometidas pelos pais ${ }^{29}$. Exercida de forma crônica, pode causar prejuízos para o desenvolvimento psicossocial e cognitivo, comprometendo seriamente a saúde emocional das vítimas ${ }^{27,30}$.

A violência sexual foi verificada em cinco crianças. Mesmo sendo considerado crime que acomete milhares de pessoas em todo o mundo ${ }^{31}$ a real prevalência das agressões sexuais é pouco conhecida, devido ao medo, constrangimento, incompreensão dos familiares e amigos ${ }^{32,33}$. Portanto, torna-se um desafio constante quantificar melhor a violência sexual, por estar diretamente ligada a tabus culturais, relações de poder no âmbito familiar e culpabilização da vítima ${ }^{33}$.

A maior ocorrência de negligência familiar e violência física corrobora resultados de estudos que relatam altos índices dessas formas de violação nas diferentes faixas etárias. Pesquisa desenvolvida em 142 municípios paulistas verificou que $92,2 \%$ dos casos foram de violência doméstica, por negligência familiar e violência física ${ }^{2}$. Waiselfisz aponta que quanto mais desprotegida a vítima, maior a utilização de força física, mesmo em crianças com menos de 1 ano de idade ${ }^{31}$.
Estudos apontam que, nos Estados Unidos, cerca de $45 \%$ das agressões contra crianças constituem-se em negligência familiar ${ }^{28}$.

Essa violação de direitos, definida como a “omissão dos pais ou de outros responsáveis pela criança ou adolescente em prover as necessidades básicas para seu desenvolvimento foi responsável pela maior parte dos processos analisados ${ }^{33,34}$. Sabe-se que a negligência pode se manifestar pela ausência de cuidados físicos, emocionais e sociais, assim como pelo abandono da criança desde a mais tenra idade. Essas situações discriminadas como violência no interior da família podem se apresentar combinadas com a omissão do Estado no seu dever constitucional de amparo à criança. Considerando o alto percentual de processos dessa tipologia faz-se necessário refletir sobre a linha tênue que perpassa tal questão, como responsabilizar, judicialmente, os pais pela omissão de cuidados com os filhos. Questiona-se até onde vai a negligência dos pais ou até onde o Estado é capaz de prover condições mínimas às famílias para se tornarem autônomas, emancipadas, capazes de garantir cuidado e proteção às suas crianças.

As manifestações da questão social, na forma da discriminação contra crianças e adolescentes, na fome, na miséria, no desemprego, são consequências de uma violência estrutural. Esta violência que tem como lócus privilegiado uma sociedade pseudodemocrática, pautada em leis que apesar de pregar a igualdade entre os cidadãos, não consegue garantir a todos o pleno acesso aos seus direitos, pois o Estado volta suas ações para uma determinada e privilegiada classe ${ }^{35}$.

Martins e Mello Jorge ${ }^{9}$ afirmam que as medidas de proteção aplicadas pelo Poder Judiciário às crianças e adolescentes em situação de risco são importantes para garantir o desenvolvimento biopsicossocial das vítimas e assegurar-lhes efetiva proteção. Por outro lado, o encaminhamento rotineiro à Justiça pode estar sinalizando a ausência ou ineficiência das políticas sociais, ou seja, falha nos componentes da rede de cuidados à criança que deveriam prover a família para a preservação da convivência familiar. Esse novo fenômeno societário tem sido denominado pelos juristas como "judicialização dos conflitos sociais" ou "judicialização da política" ${ }^{36-38}$. Caracteriza-se pela transferência para o Poder Judiciário da responsabilidade de enfrentamento das expressões da questão social, na expectativa da efetivação dos direitos humanos e garantia dos mínimos sociais. Moreira expressa preocupação com a regulação jurídica das relações familiares 
entre pais e filhos, mesmo como garantia da restituição de direitos violados ${ }^{22}$.

A violência física como a segunda causa de violência, acometendo todas as faixas etárias, pode ter relação direta com sua materialidade, visto ser uma forma de violência que deixa marcas visíveis, sendo também comumente naturalizada e aceita socialmente. Legitimada pela sociedade brasileira, a violência física decorre da exacerbação do poder de autoridade e proteção que $o$ adulto considera que possui na relação com a criança e está relacionada a uma representação social de prática pedagógica-familiar ${ }^{39}$. O castigo físico é considerado como uma forma de se educar e de se impor limites às crianças ainda em desenvolvimento. Punições físicas severas se constituem como grave problema mundial, atingindo crianças de diferentes culturas ${ }^{24,40}$. A violência física pode, em curto prazo, provocar incapacidade física ou mental e, ainda, ser causa de óbito.

Segundo dados da $\mathrm{OMS}^{1}$ os pais utilizam distintas formas de violência corporal contra seus filhos. Em Recife, estudo aponta que 50\% das 2.112 crianças entrevistadas foram disciplinados por meio de castigos corporais ${ }^{40,41}$, indicando a aceitabilidade cultural desse tipo de violência.

Se por um lado, a partir da Constituição Federal de 1988 e do Estatuto da Criança e do Adolescente, houve a ampliação dos direitos positivados, por outro, depara-se a cada dia, com o "encolhimento da responsabilidade do Estado e a ausência de políticas públicas consistentes ante a questão social que se expressa no âmbito familiar" $" 42,43$. $\mathrm{O}$ atendimento às necessidades básicas e imediatas não deve se transformar em prática assistencialista e sim, constituir-se como direito do cidadão de ter garantidas as condições para uma vida digna.

Entre as medidas protetivas aplicadas verificou-se a tríade orientação-apoio-acompanhamento temporário em todas as determinações judiciais, associada com inclusão em programa comunitário ou oficial de auxílio à criança, à família e ao adolescente; e/ou inclusão em programa oficial ou comunitário de auxílio, orientação e tratamento de alcoólatras e toxicômanos; e/ou transferência da guarda ou tutela a terceiros; e/ou acolhimento institucional.

De acordo com a legislação brasileira a institucionalização da criança deve ser a última medida a ser aplicada, devendo ser esgotadas todas as possibilidades de manutenção da criança no seio familiar, preservando, assim, o vínculo afetivo com a família de origem. Entretanto, o presente estudo revelou que a gravidade da situação, verificada em um quarto dos processos obrigou a determinação dessa medida extrema.

Os números expressos, no presente estudo, referentes à negligência familiar, sugerem que as políticas públicas de promoção dos direitos das crianças não tem sido exitosas, acarretando, como consequência, demandas judiciais para reparação de violações.

$\mathrm{Na}$ quase totalidade dos processos analisados a aplicação da medida protetiva, garantiu a interrupção da situação de violência. Além disso, a interlocução com os demais atores sociais possibilitou a minimização do ciclo recursivo de violência doméstica enfrentada cotidianamente pelas crianças. Se, após dois anos, em $93 \%$ dos processos as crianças saíram da situação de risco, após intervenção judicial, frente à gravidade e eminência de dano, o tempo de tramitação na esfera judicial pode ainda estar sendo demasiado longo. Na medida em que se transfere para o Judiciário a responsabilidade de atender individualmente demandas que são coletivas, corre-se o risco de desresponsabilizar o Estado. O desafio que se impõe é o de pensar na formulação e implementação de políticas públicas, voltadas para a criança, de modo articulado e integrado com o Poder Judiciário, considerando que devem ser ações complementares.

Por outro lado, não é possível tratar o complexo fenômeno da violência como questão eminentemente judicial. Uma intervenção efetiva, oportuna, pautada na garantia de direitos, na promoção, emancipação e autonomia do sujeitocidadão pressupõe ações intersetoriais planejadas e integradas, buscando evitar ações desencontradas e por vezes superpostas.

Os profissionais devem perceber a problemática da violência como focal em sua prática. Somente assim as vulnerabilidades serão reconhecidas e o fenômeno não será subestimado ${ }^{44}$. Nesse sentido, torna-se essencial a capacitação dos profissionais de saúde, educadores e técnicos do sistema judiciário para que estejam alertas e aprendam a lidar com essa temática em seu cotidiano, com ações contextualizadas na realidade, que contribuam para a efetivação de direitos e minimizem os sofrimentos dessas crianças.

\section{Considerações finais}

O estudo revelou a importância do Poder Judiciário no enfrentamento à violência praticada contra crianças e adolescentes, visto que na quase totali- 
dade dos processos analisados as crianças saíram da situação de risco, após intervenção judicial. As medidas protetivas, estabelecidas pelo Estatuto da Criança e do Adolescente se apresentaram como importante instrumento no combate à violência infantil, uma vez que possibilitam à criança proteção e acesso aos direitos garantidos em lei.

A negligência como a violação mais frequente sugere que novas demandas estão sendo apresentadas ao Poder Judiciário, na medida em que esse é convocado a intervir em situações manifestadas pelas diferentes expressões da questão social.

Apesar da importância e resolubilidade de 93\% dos processos, a superação da violência infantil demanda ações intersetoriais e multiprofissionais mais oportunas. A intervenção jurídica não esgota toda a complexidade das relações vividas pelas famílias. Um dia, um mês de convivência com o agressor podem trazer danos emocionais ou físicos irreparáveis. A morosidade é uma forma de impunidade que pode gerar graves consequências emocionais para a vítima e seus familiares e, nesta demora, a criança pode ser inclusive, revitimizada.

Para a necessária celeridade na aplicação e execução das medidas protetivas torna-se essencial maior integração entre as instituições permitindo formas articuladas de intervenção. A instância judicial não pode ser a porta de entrada da comunicação da violência. Urge fortalecer a interação dos diversos programas e setores - Assistência Social, Segurança Pública, Educação, Saúde - buscando construir fluxos e processos comuns de trabalho mais efetivos na defesa e proteção das crianças. Uma intervenção eficaz, pautada na garantia de direitos, na promoção, emancipação e autonomia do sujeito-cidadão pressupõe o envolvimento da família, da sociedade, das instituições escolares e de atenção à saúde. A garantia de direitos tem na execução das políticas públicas, e não na judicialização, o lócus privilegiado de efetivação.

\section{Colaboradores}

CLS Ferreira: planejamento da pesquisa, coleta de dados, elaboração do texto, revisão final e aprovação da versão final. ED Gontijo e MCJW Côrtes: planejamento da pesquisa, elaboração do texto, revisão final e aprovação da versão final. 


\section{Referências}

1. Organização Mundial de Saúde (OMS). Abuso infantil e negligência por parte dos pais e responsáveis. In: Krug EG, Dahlberg LL, Mercy JA, Zwi AB, Lozano R, editores. Relatório mundial sobre violência e saúde. Genebra; 2002. p. 59-87.

2. Azevedo MA, Guerra VNA. Infância e violência doméstica. 6a Edição. São Paulo: LACRI - USP; 2011.

3. Ministério da Justiça. Sistema de Informação para a Infância e Adolescência (SIPIA) [Internet]. Brasília. Disponível em: http://www.sdh.gov.br/assuntos/ criancas-e-adolescentes/programas/observatorio-nacional-dos-direitos-da-crianca-e-do-adolescente-1/ sistema-de-informacoes-para-infancia-e-adolescencia-2013-sipia

4. Brasil. Ministério da Saúde. Informações em saúde: epidemiológicas e morbidade [Internet]. [Acessado 15 Feb 2018]. Disponível em: http://www2. datasus.gov.br/DATASUS/index.php?area $=0203 \& \mathrm{i}-$ $\mathrm{d}=29892332 \& \mathrm{VObj}=\mathrm{http} / /$ tabnet.datasus.gov.br/cgi/ deftohtm.exe?sinannet/cnv/viole

5. Brasil. Ministério da Saúde. Portaria 104, de 25 de janeiro de 2011. Disponível em http://bvsms.saude.gov. br/bvs/saudelegis/gm/2011/prt0104_25_01_2011. html

6. Minayo MCS. Violência e saúde (Internet). Rio de Janeiro: Fiocruz; 2006. (Coleção Temas em Saúde). Disponível em: SciELO Books.

7. Lima JS, Deslandes SF. A notificação compulsória do abuso sexual contra crianças e adolescentes: uma comparação entre os dispositivos americanos e brasileiros. Interface Comunicação, Saúde e Educação 2011;15(38):819-832.

8. Brasil. Lei n ${ }^{\circ} .8069$ de 13 de julho de 1990. Dispõe sobre o Estatuto da Criança e do Adolescente e dá outras providências. Diário Oficial da União; 1990.

9. Martins CBG, Jorge MHPM. Desfecho dos casos de violência contra crianças e adolescentes no poder judiciário. Acta Paul Enferm 2009;22(6):800-807.

10. Eloy CB, Constantino EP. A psicologia e a judicialização dos casos de violência sexual. Psicologia Política 2012;12(23):139-152.

11. Assis SG, Constantino P. Violência contra crianças e adolescentes: o grande investimento da comunidade acadêmica na década de 90. In: Minayo MCS, Souza ER, organizadoras. Violência sob o olhar da saúde: a infrapolítica da contemporaneidade brasileira. Rio de Janeiro: Editora Fiocruz; 2003. p.163-189.

12. Gomes R, Junqueira MFPS, Silva CO, Junger WL. A abordagem dos maus-tratos contra a criança e o adolescente em uma unidade pública de saúde. Ciên Saude Colet 2002;7(2):275-283.

13. Deslandes SF. Atenção a crianças e adolescentes vítimas de violência doméstica: análise de um serviço. Cad Saude Publ 1994;10(Supl. 1):177-187.

14. De Lorenzi DRS, Pontalti L, Flech RM. Maus tratos na infância e adolescência: análise de 100 casos. Revista Cientifica da AMECS 2001;10(1):47-52.

15. Nunes AJ, Sales MCV. Violência contra crianças no cenário brasileiro. Ciên Saude Colet 2016;21(3):871-880

16. Faleiros JM, Matias ASA, Bazon MR. Violência contra crianças na cidade de Ribeirão Preto, São Paulo, Brasil: a prevalência dos maus-tratos calculada com base em informações do setor educacional. Cad Saude Publica 2009;25(2):337-348.
17. Lobato GR, Moraes CL, Nascimento MC. Desafios da atenção à violência doméstica contra crianças e adolescentes no Programa Saúde da Família em cidade de médio porte do Estado do Rio de Janeiro, Brasil. Cad Saude Publica 2012;28(9):1749-1758.

18. Nunes CB, Sarti CA, Ohara CVSO. Profissionais de saúde e violência intrafamiliar contra a criança e adolescente. Acta Paul Enferm 2009;22(n.esp):903-908.

19. Saffioti HIB. No fio da navalha: violência contra crianças e adolescentes no Brasil atual. In: Madeira FR, organizadora. Quem mandou nascer mulher? Estudos sobre crianças e adolescentes pobres no Brasil. Rio de Janeiro: Record/Rosa dos Tempos; 1997. p. 137-211.

20. Assis SG, Deslandes SF. Abuso físico em diferentes contextos de socialização infanto-juvenil. In: Lima CA, coordenadora. Violência faz mal à saúde. Brasília: Ministério da Saúde (MS); 2004. p.47-57.

21. Mioto RCT. Novas propostas e velhos princípios: a assistência às famílias no contexto dos programas de orientação e apoio sociofamiliar. In Sales M, Matos MC, Leal MC, organizadores. Política social, família e juventude: uma questão de direitos. $2^{\text {a }}$ Edição. São Paulo: Cortez; 2006. p. 43-59.

22. Moreira, MIC. Os impasses entre acolhimento institucional e o direito à convivência familiar. Psicologia of Sociedade 2014;26(n. spe. 2):28-37.

23. Brasil. Ministério da Saúde. Secretaria de Políticas de Saúde. Violência intrafamiliar: orientações para a prática em serviço [Internet]. Brasília: Ministério da Saúde; 2001. [Acessado 2014 Oct 14]. Disponível em: http://bvsms.saude.gov.br/bvs/publicacoes/cd05_19. pdf

24. Minayo MCS. Vulnerabilidade à violência intrafamiliar. In: Lima FR, Santos C, coordenadores. Violência doméstica: vulnerabilidades e desafios na intervenção criminal e multidisciplinar. Rio de Janeiro: Lumen Juris; 2010.

25. Zimermann CR. Os Programas Sociais sob a Ótica dos Direitos Humanos: o caso do bolsa família do governo Lula no Brasil. SUR - Rev. Internac.de Dir. Hum 2006,3(4):145-159.

26. Menezes TC, Amorim MMR, Santos LC, Faúndes A. Violência física doméstica e gestação: resultados de um inquérito no puerpério. Rev Bras Ginecol Obstet 2003;25(5):309-316.

27. Assis SG, Avanci JQ. Abuso psicológico e desenvolvimento infantil. In: Brasil. Ministério da Saúde. Violência faz mal à saúde. Brasília: Ministério da Saúde; 2004. p. 59-67.

28. Benetti SPC. Maus tratos da criança: abordagem preventiva. In: Hutz CS, organizador, Reppold CT, Pacheco J, Bardagi M, Hutz CS, Benetti SPC, Silva DFM, Lisboa CSM, Koller SH. Situações de risco e vulnerabilidade na infância e na adolescência: aspectos teóricos e estratégias de intervenção. São Paulo: Casa do Psicó$\log$; 2002. p.131-150.

29. Assis SG. Crescendo em meio às dificuldades: o jovem e sua família. In: Assis SG. Traçando caminhos em uma sociedade violenta: a vida de jovens infratores e de seus irmãos não-infratores. Rio de Janeiro: Fiocruz; 1999. p.41-64. 
30. Santana JSS, Souza SL. Violência em situação de rua. In: Costa COM, Souza RP organizadores. Adolescência: aspectos clínicos e psicossociais. Porto Alegre: Artmed; 2002. p.439-448.

31. Waiselfisz JJ. Mapa da violência 2012: Crianças e adolescentes do Brasil [Internet]. Rio de Janeiro: Centro Brasileiro de Estudos Latino-Americanos, FLACSO Brasil; 2012. [Acessado 14 Oct 2014]. Disponível em: http://goo.gl/ZXIV3U

32. Habigzang LF, Koller SH, Azevedo GA, Machado PX. Abuso sexual infantil e dinâmica familiar: aspectos observados em processos jurídicos. Psic Teor e Pesq 2005;21(3):341-348.

33. Costa COM, Carvalho RC, Santa Bárbara JFR, Santos CAST, Gomes WA, Sous HL. O perfil da violência contra crianças e adolescentes, segundo registros de Conselhos Tutelares: vítimas, agressores e manifestações de violência. Ciên Saude Colet 2007;12(5):1129-1141.

34. Souza ER, Mello Jorge MHP. Impacto da violência na infância e adolescência brasileiras: magnitude da morbimortalidade. In: Lima CA, coordenadora. Violência faz mal à saúde. Brasília: Ministério da Saúde; 2004. p.23-28.

35. Cruz Neto O, Moreira MR. A concretização de políticas públicas em direção à prevenção da violência estrutural. Ciên Saude Colet 1999;4(1):33-52.

36. Esteves JL. Cidadania e judicialização dos conflitos sociais. Rev Direito Público 2006;1(2):41-54.

37. Melo ALA. A judicialização do estado brasileiro, um caminho antidemocrático e monopolista [Internet]. Jus Navigandi 2001;6(52). [Acessado 28 Apr 2015]. Disponível em: jus.uol.com.br/revista/texto/2408

38. Vianna LW, Carvalho MAR, Melo MPC, Bargos MB, organizadores. A judicialização da política e das relações sociais no Brasil. Rio de janeiro: Revan; 1999.
39. Donoso TVM. Representações sociais das famílias sobre violência física na infância como forma de educação. [tese]. Belo Horizonte: Faculdade de Medicina, Universidade Federal de Minas Gerais; 2006.

40. Guerra VNA. Violência de pais contra filhos: a tragédia revisitada. São Paulo: Cortez; 2001.

41. Gomes R, Almeida ABB, Ecteins IB, Solter M, Paiva SCS. A saúde e o direito da criança ameaçados pela violência. Rev Latino-AmEnferm 1999;7(3):5-8.

42. Vitale MAF. Famílias monoparentais: indagações. Revista Serv. Social e Sociedade 2002;Edição especial(71). apud Cartolo CM. A chefia familiar feminina nas famílias monoparentais em situação de extrema pobreza. Rev Virtual Textos e Contextos 2005;4(1):117.

43. Cartolo CM. A chefia familiar feminina nas famílias monoparentais em situação de extrema pobreza. Rev Virtual Textos e Contextos 2005;4(1):1-17.

44. Apostólico MR, Hino P, Egry EY. As possibilidades de enfrentamento da violência infantil na consulta de enfermagem sistematizada Rev Esc Enferm USP 2013;47(2):320-327.

Artigo apresentado em 27/09/2017

Aprovado em 16/04/2018

Versão final apresentada em 18/04/2018 